\title{
OBTENÇÃO DO ETANOL A PARTIR DO REAPROVEITAMENTO DOS REJEITOS DO PROCESSO DE PRODUÇÃO DA CACHAÇA
}

\section{ARTIGO ORIGINAL}

LOURENÇO, Caroline Ashelley da Silva ${ }^{1}$

TOLEDO, Jady Cristina Nascimento ${ }^{2}$

BIANCHI, Roberta Martins da Costa ${ }^{3}$

LOURENÇO, Caroline Ashelley da Silva. TOLEDO, Jady Cristina Nascimento. BIANCHI, Roberta Martins da Costa. Obtenção do etanol a partir do reaproveitamento dos rejeitos do processo de produção da cachaça. Revista Científica Multidisciplinar Núcleo do Conhecimento. Ano 05, Ed. 04, Vol. 01, pp. 29 54. Abril de 2020. ISSN: 2448-0959, Link de acesso: https://www.nucleodoconhecimento.com.br/engenharia-quimica/obtencaodo-etanol

\section{RESUMO}

Atualmente existem duas metodologias para a fabricação de cachaça, a artesanal e a industrial. A fabricação artesanal ocorre por meio de um equipamento conhecido como alambique. A produção industrial acontece em um equipamento chamado de coluna fracionada com o objetivo de conseguir uma produção em maior proporção. Devido à pequena escala de produção, a cachaça artesanal se destaca em relação à cachaça industrial, por obter uma qualidade sensorial superior. Porém, para que esta qualidade

\footnotetext{
${ }^{1}$ Engenheira Química pela Universidade São Francisco.

2 Engenharia Química pela Universidade São Francisco.

${ }^{3}$ Professora na Universidade São Francisco, Doutora em Nanociências e Materiais Avançados pela Universidade Federal do ABC (UFABC); Química Industrial pela Universidade São Francisco (USF).
} 
seja mantida, na etapa de fabricação e destilação, deve-se ter um cuidado maior, separando as partes do destilado, conhecidas como cabeça e cauda, que não podem ser agregadas ao produto final, pois caracterizam aroma desagradável ao produto, além de ser prejudicial à saúde do consumidor. Desta forma os produtores atualmente separam estas frações, mas acabam descartando-as de formam incorreta. O presente trabalho visa utilizar os rejeitos do processo de destilação da cachaça, cabeça e cauda, para a obtenção de um novo subproduto, o etanol combustível. Este novo produto além de trazer renda e aumentar a viabilidade do negócio, também evita que estes rejeitos sejam descartados de forma inadequada. Para a verificação de viabilidade desta conversão, foi reproduzida em escala laboratorial a produção da cachaça para obtenção dos rejeitos, cabeça e cauda, a fim de aumentar a graduação alcoólica dos mesmos, para assim obter o etanol combustível.

Palavras-chave: Cachaça, rejeito, reaproveitamento, processo, destilação.

\section{INTRODUÇÃO}

A origem da cana-de-açúcar no Brasil se deu desde a época colonial, pois apesar de a mesma não ser natural do país se adaptou muito bem as condições climáticas tropicais existentes. As regiões em que houve produções em maior escala estavam localizadas próximo ao litoral, e seu principal uso foi após a criação dos engenhos produtores de açúcar (na época moeda de escambo) e assim se tornou desde então um potencial econômico. De acordo com a Nova Cana (2018), o Brasil apresenta a terceira cultura temporária em termos de ocupação de área relacionada ao cultivo da cana-de-açúcar, com uma produtividade média de aproximadamente 75 T/ha.

A partir da cana-de-açúcar são gerados alguns produtos, dentre os principais encontra-se a cachaça. A cachaça ou caninha também chamada de aguardente é a bebida mais antiga e consumida no Brasil, sendo sua produção estimada em 1,3 bilhões de litros por ano. Desta produção, 90\% é obtida de modo industrial e 10\% artesanal, gera receita da ordem de US\$500 milhões e emprega cerca de 450 mil 
pessoas (ALAMBIQUE DA CACHAÇA, 2018). A cachaça artesanal comumente conhecida como aguardente é o produto gerado a partir da fermentação do caldo-dacana que em seguida passa por um processo de destilação. Sua obtenção ocorre em locais denominados de alambiques apresentando como principal característica a qualidade, esse fato é devido à pequena escala de fabricação.

A produção de cachaça em escalas pequenas representa uma alternativa de geração de renda para os envolvidos além de, muitas vezes se tornar uma tradição familiar passando de geração para geração. O processo de fabricação desta bebida assim como na maioria dos processos produtivos de qualquer produto de forma geral, acaba gerando resíduos, que são descartados na maioria das vezes, ou podem ser reaproveitados no mesmo processo de fabricação ou mesmo para a geração de outros produtos. Os principais resíduos gerados na produção da cachaça artesanal são o bagaço da cana, vinhoto, água de resfriamento. Além disso, no destilado encontra-se a cabeça e cauda e não podem ser utilizadas para produção da bebida por apresentarem um alto teor alcoólico. A cabeça é a primeira fração do destilado e representa de $5 \%$ a $10 \%$ do destilado total, já a cauda representa a parte final com um percentual de $10 \%$ a $15 \%$ do destilado total (OLIVEIRA et al., 2005).

Estas duas frações descartadas do processo de destilação na fabricação da cachaça artesanal podem representar de $15 \%$ a $25 \%$ do destilado total, representando um valor significativo em termos de custo e volume de produção. Como a cachaça artesanal é produzida comumente em pequenos atributos e na maioria das vezes, os produtores não possuem rendimentos lucrativos suficientes para implantação de um sistema sustentável, os rejeitos são descartados em recursos hídricos como rios e córregos. Estes despejos quando descartados inadequadamente, podem proporcionar a mortandade da vida aquática, além de tornar a água não potável devido ao seu teor alcoólico e aumento de $\mathrm{pH}$ do meio. Como possibilidade para diminuição do impacto ambiental gerado a partir do descarte destas frações, seria o aproveitamento deste resíduo para a geração de novos produtos, como, por exemplo, a produção do etanol combustível, 
obtido a partir da redestilação dos rejeitos cabeça e cauda. O etanol foi introduzido no mercado nacional, desde a criação do plano Programa Nacional do Álcool (Pró-Álcool) em 1975, com o objetivo de reduzir a dependência nacional em relação ao petróleo importado como fonte de energia, reduzindo também os impactos ambientais gerados, substituindo um combustível fóssil por um combustível "limpo" (LEITE e CORTEZ, 2008). Com isso, produzir um combustível ambientalmente "limpo" a partir de um rejeito de um processo tornaria ambientalmente sustentável, além de uma nova fonte geradora de recursos econômicos, para os pequenos produtores de cachaça artesanal.

O objetivo desse trabalho é utilizar os resíduos cabeça e cauda por meio da operação unitária destilação para a obtenção do etanol combustível. Com isso, verificar a viabilidade deste processamento, reduzindo os impactos ambientais que são gerados com o descarte inadequado destes rejeitos no meio ambiente a fim de promover uma forma de renda extra aos pequenos produtores de cachaça artesanal.

\section{CANA-DE-AÇÚCAR}

Em certo período da história do Brasil Colonial, compreendido entre meados do século $\mathrm{XVI}$, a cana-de açúcar por apresentar boa adaptação aos solos brasileiros se tornou uma das principais culturas da época. Durante este período foi intensamente cultivada ao longo da costa do Brasil, apresentando ótimos resultados especialmente no Recôncavo Baiano e Pernambuco. $O$ cultivo da cana-de-açúcar para fins comerciais ocorre em mais de 70 países, sendo Brasil, Índia e China os maiores produtores. A distribuição do plantio de cana-de-açúcar concentra-se fortemente no estado de São Paulo, apresentando um percentual de 62\%, seguido por Goiás e Minas Gerais. Existe um aumento cada vez maior na produção, considerando dados da safra de 2015 para 2016, onde foi observado um aumento de 3,8\%, sendo que, a produção só não foi maior, porque houve redução de área plantada e o estado responsável pela maior produção sofreu impacto hídrico, devido à falta de chuva no ano (FONTANETTI e BUENO, 2017). A cana-de-açúcar se tornou uma potência econômica no Brasil devido à grande variedade de subprodutos gerados a partir da extração do caldo. Dentre os 
vários produtos que existem, os que mais se destacam em relação a produtividade e impacto econômico são o açúcar, o álcool combustível e a aguardente, popularmente conhecida Omo cachaça (FONTANETTI e BUENO, 2017).

\subsection{CACHAÇA OU AGUARDENTE}

A aguardente ou cachaça teve sua existência ainda na época escravocrata, onde os negros foram os primeiros a descobrirem esta nova bebida. O método já era conhecido e consistia em moer a cana através de moenda para obter o caldo. O caldo era fervido e posteriormente adicionados em formas para resfriar, obtendo então um produto chamado de rapadura, utilizada para adoçar as bebidas. Mas, algumas vezes, este caldo perdia a característica desejada por fermentar, formando um produto denominado "cagaça". A cagaça era jogada fora, por não apresentar um sabor doce para adoçar as bebidas. Com isso os escravos a tomavam e se embriagavam, como conseqüência trabalhavam aparentemente mais alegres. Os dos donos de engenhos começaram a incentivar seus escravos a consumirem a cachaça. Com o decorrer do tempo esta bebida obteve uma qualidade melhor após ser destilada e filtrada. Devido à cachaça na maioria das vezes ser consumida por pessoas de baixa renda, ou mesmo na clandestinidade, como era pelos escravos, começou a ser associada a uma bebida de má qualidade. Com o tempo e a partir de melhorias realizadas no processo de fabricação, começou a ser apreciada e respeitada por pessoas de alto poder aquisitivo, como políticos e até embaixadores em reuniões internacionais. Por muito pouco a cachaça não teve sua marca registrada pela França. Atualmente a cachaça é considerada como uma bebida característica do brasil, e em 2002 o então presidente Fernando Henrique Cardoso assinou o decreto 4.702 declarando a cachaça como um destilado de origem nacional, mas apreciado em todos os cantos do mundo (ALAMBIQUE DA CACHAÇA, 2018).

A aguardente de cana trata-se da bebida destilada mais consumida no Brasil, se destacando em primeiro lugar e em terceiro lugar no cenário mundial. Conforme Programa Brasileiro de Desenvolvimento da Aguardente de Cana, Caninha ou Cachaça (PBDAC), a produção gira em torno 1,3 bilhões de litros por ano, sendo $25 \%$ 
trata-se da produção artesanal e 75\% produção industrial. O Brasil consome praticamente toda a produção de cachaça do país, exportando apenas de $1 \%$ a $2 \%$, para outros países, como Alemanha, Paraguai, Itália, Uruguai e Portugal (SAKAI, 2006). A produção de cachaça pode ser obtida por duas maneiras sendo a industrial e artesanal.

$\mathrm{Na}$ forma de produção industrial a qualidade do produto final é inferior à sua forma de produção artesanal, pois a fabricação em larga escala, que ocorre geralmente em grandes fazendas produtoras utilizam colunas de destilação, tonéis de aço inox e na fermentação são adicionados produtos químicos e além de não separar a parte nobre do destilado dos outros componentes que podem comprometer a qualidade do produto final. A cachaça obtida de forma artesanal se destaca pela alta qualidade, ocasionada pela pequena escala de produção e todo o cuidado dos pequenos produtores com relação à fermentação que ocorre de forma natural, há separação das partes do destilado, a estocagem é feita em barris de madeira para melhorar a qualidade do produto final. Hoje no país existem mais de 40.000 produtores de cachaça artesanal, abrangendo mais de 4.000 marcas diferentes (SAKAI, 2006).

\subsection{PROCESSO PRODUÇÃO DA CACHAÇA ARTESANAL}

O processo de produção da cachaça artesanal possui basicamente as mesmas etapas de fabricação do etanol (Fluxograma 1). A fabricação inicia-se a partir da colheita da cana-de-açúcar, que é direcionada até o engenho. No engenho, a matéria-prima é recebida e estocada em local preferencialmente limpo, seco, com piso impermeável a fim de se evitar a contaminação, até ser levado à moagem (SAKAI, 2006).

\subsection{MOAGEM}

O processo de moagem consiste na inserção da cana-de-açúcar no equipamento chamado moenda, conforme mostrado Figura 1, que possui rolos responsáveis por comprimirem a cana até a separação do caldo do bagaço, onde essa etapa deve acontecer o mais breve possível no período máximo de 24 horas após a colheita da 
cana, a fim de se evitar a deterioração da matéria-prima e seus componentes. A moenda deve ter seus rolos ajustados de acordo com as características de cada matéria-prima a fim de se evitar qualquer desperdício no processo (OLIVEIRA et al., 2005).

O caldo de cana obtido após a etapa da moagem pode sair com impurezas como terra, pedaços de palha, bagacilhos que podem prejudicar a fermentação do caldo, trazendo contaminantes para o meio. Devido a isso, o caldo deve passar por uma etapa de filtração e em seguida ser encaminhado para um decantador a fim de remover todas estas impurezas. Depois do processo de purificação do caldo, é realizada a medição do índice de açúcar no meio e com o acréscimo de água ou não se realiza a correção deste índice denominado de grau Brix. Em seguida o caldo é encaminhado para os recipientes onde ocorrerá a fermentação, conhecido também como dornas de fermentação. Esta etapa de diluição do meio é extremamente importante, pois influência diretamente no rendimento da fermentação, que é responsável pela conversão de açúcar em álcool (OLIVEIRA et al., 2005). 
Fluxograma 1. Produção da cachaça.

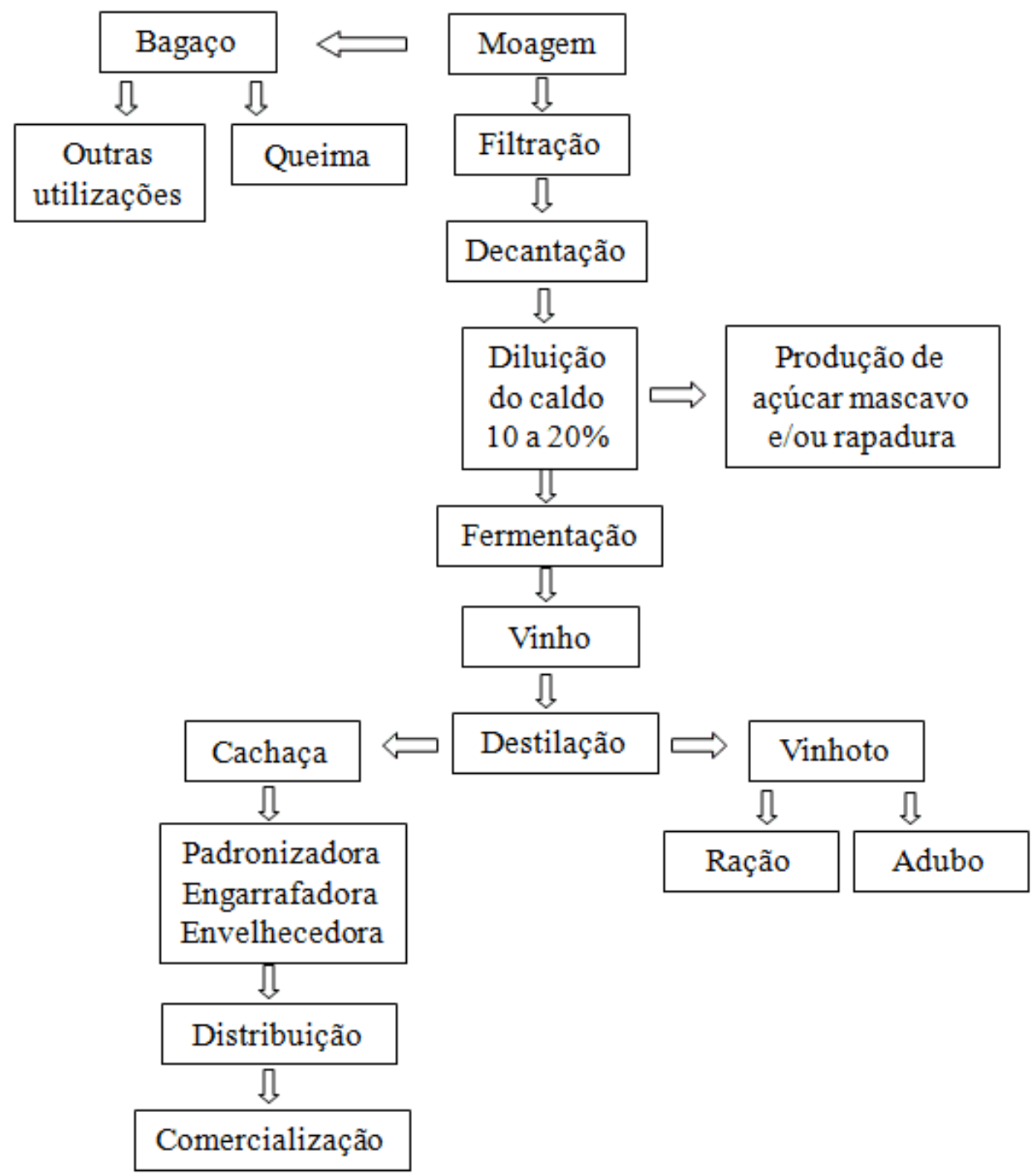

Fonte: SAKAI, 2006, adaptado. 
Figura 1. Exemplo de uma Moenda.

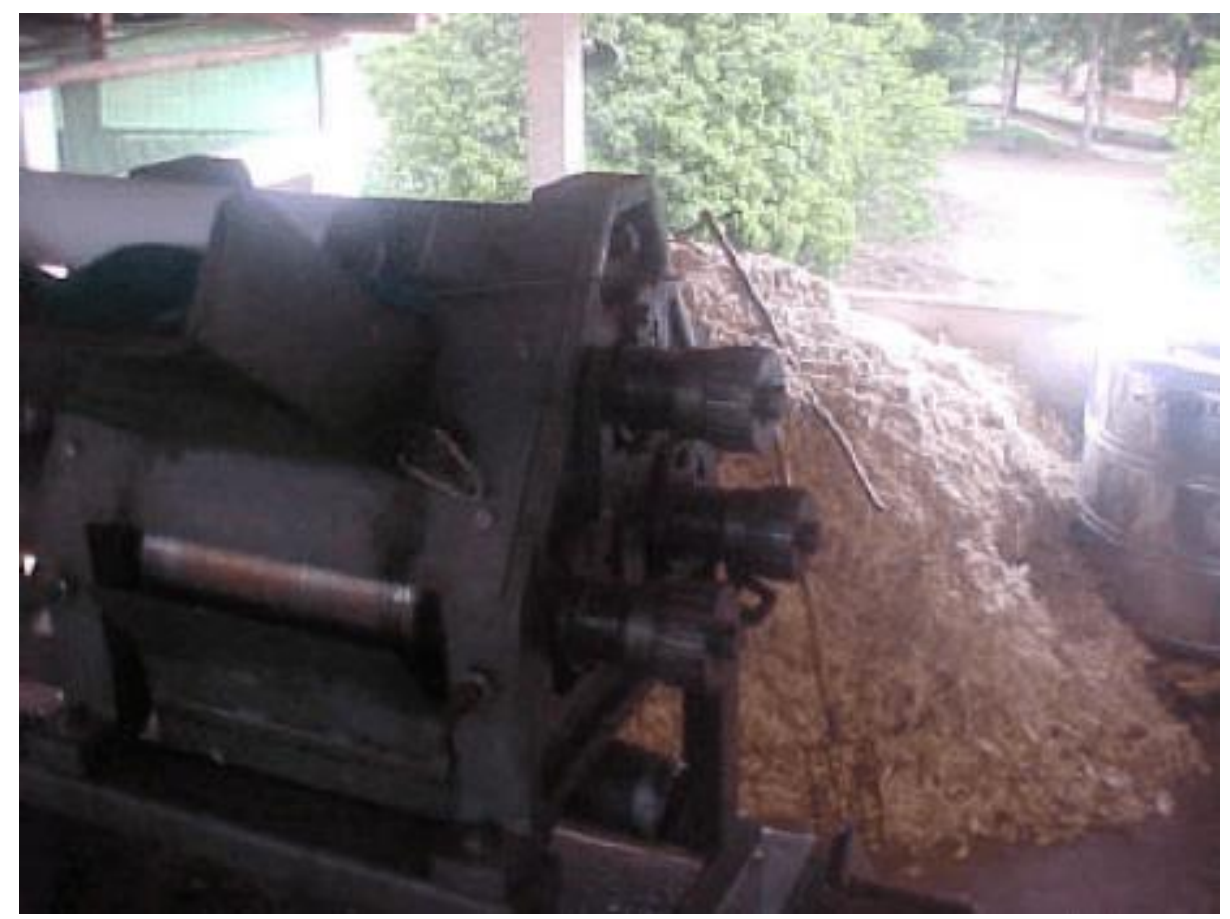

Fonte: OLIVEIRA et al., 2005.

\section{DETERMINAÇÃO DO GRAU BRIX}

Para determinar a quantidade de sólidos solúveis em uma solução de sacarose utilizase a escala numérica chamada de Brix (símbolo ${ }^{\circ} \mathrm{Bx}$ ). Esta escala foi derivada originalmente da escala de Balling, a partir da temperatura de referência de 15,5 $5^{\circ} \mathrm{O}$ grau Brix trata da quantidade de sólidos solúveis no sumo de frutas e em outros produtos líquidos, como o caldo-de-cana, melado, melaço e xarope de frutas. Portanto, $1 \mathrm{~g}$ de sólidos solúveis em suspensão em $100 \mathrm{~g}$ de solução $(\% \mathrm{~m} / \mathrm{m}$ ou \% $\mathrm{m} / \mathrm{v}$ ) a uma determinada temperatura, trata-se de uma unidade de Brix (SANTOS et al., 2016). Normalmente, o caldo proveniente de cana moída no ponto ideal de maturação apresenta teor de açúcares entre $18^{\circ}$ a $22^{\circ}$ Brix. Para obter o valor de $15^{\circ}$ Brix, faz-se necessário diluir o caldo de cana com água limpa, inodora, incolor, e dentro dos padrões de potabilidade para manter a estabilidade do fermento ao longo do período fermentativo. Teores de açúcares acima de 15ำ Brix promovem fermentações lentas e frequentemente incompletas, que dificulta a multiplicação do 
fermento. Para uma melhor eficiência e multiplicação do fermento é importante manter o teor de açúcar abaixo de 15ํㅡㄹ Brix (OLIVEIRA, 2011).

\subsection{PROCESSO DE FERMENTAÇÃO}

Atualmente para a fermentação alcoólica, dentre os microrganismos, o mais utilizado é a levedura. As leveduras são seres geralmente unicelulares, nos quais se diferenciam das bactérias em relação ao seu tamanho, pois são significativamente maiores dos que as bactérias, e com isso se destacam positivamente num processo que envolve destilação, sendo que nestes processos são utilizadas força centrífuga para separação do mosto fermentado. Atualmente a levedura que mais destaca na fermentação alcoólica, é a do tipo Saccharomyces cerevisiae. Este tipo de levedura pode se reproduzir de forma sexuada ou assexuada, mas em ambientes favoráveis para seu desenvolvimento como no caso do ambiente da fermentação alcoólica, rico em nutrientes, a forma assexuada é a que mais ocorre. Na fermentação do caldo-decana pelo $S$. cerevisiae, ocorre primeiramente a hidrolise pela enzima invertase $(\beta$-dfrutosidase) da sacarose existente no meio, e assim obtém-se a glicose e a frutose, em seguida estes dois componentes são convertidas pela enzima zimase em etanol e gás carbônico (ROTEIRO CACHAÇA, 2018), conforme descrito na reação abaixo.

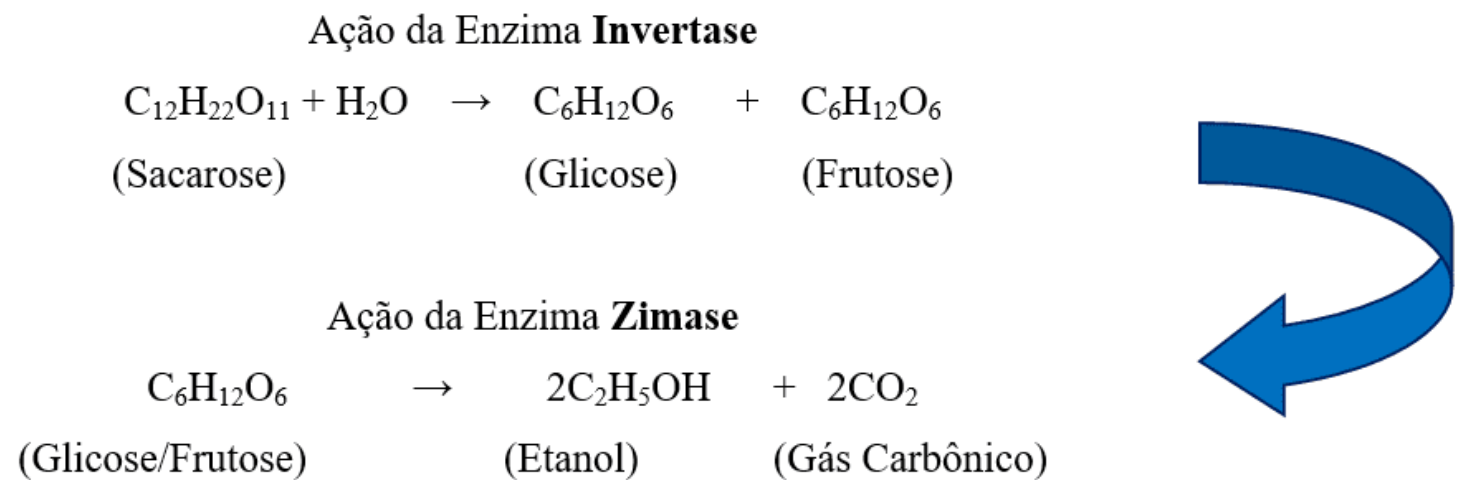

O processo de fermentação para a produção da cachaça ocorre em três etapas: (i) fermentação preliminar (pré-fermentação), (ii) fermentação principal (tumultuosa) e (iii) 
fermentação complementar (pós-fermentação). A fermentação preliminar consiste na etapa em que as leveduras estão se adaptando ao meio, sem a conversão de sacarose e etanol. Já a fermentação principal, é a etapa onde ocorre a conversão da sacarose em etanol e a liberação de gás carbônico, com isso gerando muita espuma no mosto. Na etapa complementar ocorre a conversão de alguns açúcares que ainda restam no mosto, gerando pouco álcool e liberação de gás carbônico, sendo que após completar a fermentação a superfície do mosto fica limpa e sem espumas. Com isso, a parte mais densa do mosto que consiste no fermento, se decanta no fundo da dorna e produz uma camada conhecida como pé-de-cuba. Este pé-de-cuba pode ser utilizado posteriormente para ajudar na próxima fermentação, podendo ser um nutriente para as leveduras. Já a parte sobrenadante, conhecida como vinho é separada e encaminhada para a destilação. $O$ tempo para fermentação pode variar entre 16 e 24 horas, e consegue-se saber se este tempo se encerrou após a realização da medição do grau BRIX do meio, que deve apresentar valor zero (VIANA et al., 2008).

\subsection{DESTILAÇÃO DO VINHO, ARMAZENAMENTO E EMBALAGEM}

Após o término da fermentação o vinho é encaminhado para a etapa de destilação. $\mathrm{Na}$ produção da cachaça artesanal, o vinho é encaminhado para destiladores conhecidos como alambiques, Figura 2. Nestes alambiques através do aquecimento, proporcionado na maioria das vezes por queima do próprio bagaço, a parte alcoólica do meio convertido na fermentação, evapora, devido à diferença dos pontos de ebulição e são direcionados para as serpentinas que estão resfriadas. Devido à circulação de água, ocorre a condensação do líquido sendo recolhido em outro recipiente (VIANA et al., 2008). O destilado é fracionado em três partes diferentes de acordo com o teor alcoólico, onde se obtém a cabeça correspondente a primeira fração, representando cerca de $10 \%$ do destilado total com um teor alcoólico superior a $48 \% \mathrm{v} / \mathrm{v}$. O coração que é a parte principal do destilado que corresponde à cachaça, representa até $80 \%$ do volume total de destilado apresentando um teor alcoólico entre $38 \%$ a $48 \% \mathrm{v} / \mathrm{v}$, o restante é conhecido como cauda e pode apresentar um percentual de $5 \% \mathrm{v} / \mathrm{v}$ com um teor alcoólico inferior a $38 \% \mathrm{v} / \mathrm{v}$. Os valores devem ser calculados

Disponível em: https://www.nucleodoconhecimento.com.br/engenharia-quimica/obtencao-do- 
a partir da quantidade de destilado aproximado que irá obter e determinar as quantidades das frações cabeça e cauda a partir das porcentagens descritas acima (VIANA et al., 2008). A cachaça obtida é encaminhada para o armazenamento. Com relação a cachaça artesanal, o produto final é armazenado em barris de madeira, por no mínimo seis meses, para então ser comercializada (VIANA et al., 2008).

Figura 2. Destilador do tipo alambique.

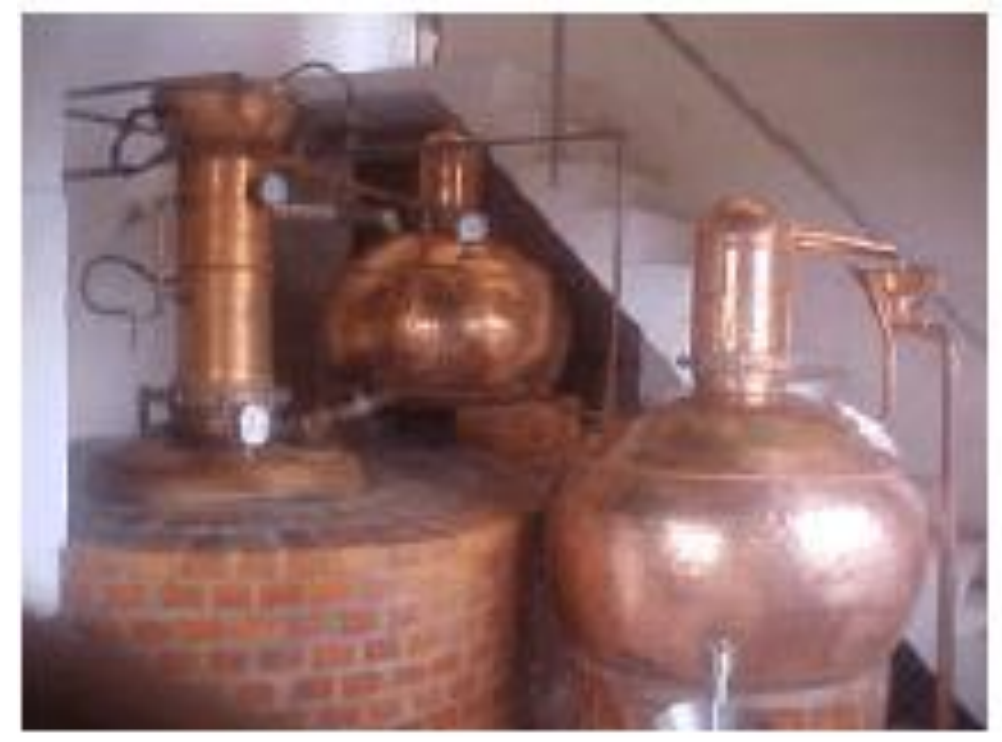

Fonte: OLIVEIRA et al., 2005.

\subsection{REJEITOS DO PROCESSO DE PRODUÇÃO DA CACHAÇA E O SEU APROVEITAMENTO}

São gerados vários rejeitos no processo de produção da cachaça, desde a colheita e moagem com a geração das palhas e do bagaço da cana até a destilação que gera as partes do destilado que não podem ser aproveitadas como a cabeça e a cauda. Estas duas frações da destilação podem possuir um alto potencial para a geração de outros produtos por possuírem em sua composição química, componentes como metanol, aldeídos, alcoóis superiores, ácidos voláteis, e justamente por apresentarem esta composição não podem ser englobados ao produto final, por ser nocivo à saúde humana (VIANA et al., 2008). A fim de diminuir os impactos ambientais, produzidos a

Disponível em: https://www.nucleodoconhecimento.com.br/engenharia-quimica/obtencao-doetanol 
partir do descarte inadequado destas duas frações do destilado que são a cabeça e a cauda, e também buscar uma nova fonte geradora de recursos para os pequenos produtores de cachaça artesanal, buscou-se então a produção de etanol a partir destas frações (cabeça e cauda), (VIANA et al., 2008).

Conforme ocorrem as produções da cachaça artesanal estas duas frações são separadas em recipiente limpo e seco, até que se consiga um volume significativo. Em seguida, as mesmas são alocadas na dorna de destilação do alambique e passam por um processo de redestilação novamente, obtendo assim uma fração com teor alcoólico maior do que na primeira destilação na produção da cachaça, conhecido também como etanol combustível (VIANA et al., 2008).

\section{METODOLOGIA}

O trabalho em questão foi desenvolvido em escala laboratorial conforme metodologia descrita por Daolio (2012). Os equipamentos utilizados possuem a mesma função dos equipamentos que possam existir em um alambique de pequeno porte utilizado para a fabricação da cachaça artesanal. Assim, pretende-se obter dados próximos da realidade, verificando posteriormente a viabilidade e possíveis ajustes que precisam ser realizados para a ampliação na escala de produção real.

\section{MOAGEM}

Inicialmente preparou-se a matéria-prima a ser utilizada, conhecida como garapa ou caldo de cana, obtido através da prensagem da cana por rolos, no equipamento chamado moenda, (Figura 1), obtendo-se um total de 4 litros de caldo de cana. Este equipamento separa por pressão a parte líquida que consiste na garapa, da parte sólida, o bagaço. Após a extração, a garapa foi alocada em um recipiente e realizada a verificação do teor de açúcar do meio, para que fosse obtida a melhor fermentação possível. 


\section{DETERMINAÇÃO DO GRAU BRIX}

A medição é realizada em graus Brix, por um aparelho conhecido como Sacarímetro (Figura 3), que consiste na concentração de açúcar no meio. Cada grau Brix equivale a $1 \%$ em peso de massa de sacarose, ou seja, $1^{\circ}$ Brix é igual a $1 \mathrm{~g}$ de sacarose por 100 gramas de solução.

Figura 3. Sacarímetro Brix

Fonte: Hexis Científica, 2018.

Conforme descrito por Daolio (2012), normalmente o caldo de cana apresenta um teor de $14^{\circ}$ a $22^{\circ}$ Brix, sendo que o valor ideal é de $15^{\circ}$ Brix. No experimento em questão, obteve-se um valor de $22^{\circ}$ Brix, com isso observou-se, portanto, que o mosto obtido apresentava teor de açúcar acima do ideal e que podem promover fermentações mais lentas e até mesmo incompletas (OLIVEIRA, 2011). Dessa maneira, foi necessário 
realizar a correção do meio, acrescentando-se água potável para a diluição do mosto. Após realizar a medição com o Sacarímetro, subtraiu-se o valor obtido da medição do valor de $15^{\circ}$ Brix e o valor da diferença foi a quantidade de água a ser acrescida ao meio reacional, conforme cálculo realizado.

- Valor Ideal Teórico para quantidade de açúcar no caldo-de-cana: 15 Brix

- Valor obtido na amostra: 22ํㅡㄹ Brix

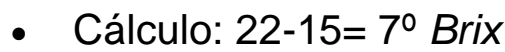

Como cada grau Brix corresponde a 1 litro de água, dividiram-se os 4 litros em sete partes e acrescentou-se ao caldo-de-cana um sétimo deste valor obtido de água:

Ex: 4/7=0,571 litros ou $571 \mathrm{~mL}$ de água a adicionar.

A diluição ocorreu pela adição de $571,0 \mathrm{~mL}$ de água potável sob homogeneização com o auxílio de uma bagueta de vidro e verificou-se novamente com o sacarímetro que o valor ideal, após a diluição foi alcançado obtendo um valor de $15^{\circ}$ Brix.

Em seguida, adicionou-se ao caldo-de-cana o fermento biológico (Tablete - Mauri), Sacharomices Cerevisiae, que conforme descrito por Daolio (2012) deve obedecer a proporção 1:12 gramas de fermento por litro de mosto. Deste modo realizou-se o cálculo por regra de três conforme descrito abaixo para verificação da quantidade de fermento a ser acrescentada ao meio reacional:

1 litro de mosto ou caldo de cana $12 \mathrm{~g}$ fermento (Tablete - Mauri)

4,571 litros de mosto ou caldo de cana ------- X g de fermento (Tablete - Mauri)

$\mathrm{X} \mathrm{g}$ de fermento $=54,9 \mathrm{~g}$ de fermento a ser acrescidos

Com o resultado dos cálculos, foi feito o acréscimo do fermento ao mosto sob homogeneização do meio, para dissolução do mesmo. Essa homogeneização foi realizada em um recipiente limpo e seco e que após a dissolução permaneceu fechado de modo a permitir que a fermentação ocorra sob condições ótimas (Daolio, 2012), 
com temperatura controlada entre $28 \stackrel{\circ}{\circ} \mathrm{C}$ a $30 \stackrel{\circ}{\circ} \mathrm{C}$ por um equipamento chamado termômetro, até o término da fermentação que dura aproximadamente 24 horas. Finalizada a fermentação, foi retirada uma quantia de $375,0 \mathrm{~mL}$ do mosto e colocado no balão de fundo redondo com duas vias, conectado a um condensador Grahan (Serpentina) contendo circulação de água para que haja resfriamento dos vapores. $O$ balão de fundo redondo foi aquecido por um bico de Bunsen e na outra entrada foi colocado um termômetro para a verificação da temperatura, conforme, Figura 4.

Figura 4. Representação do aquecimento do mosto.

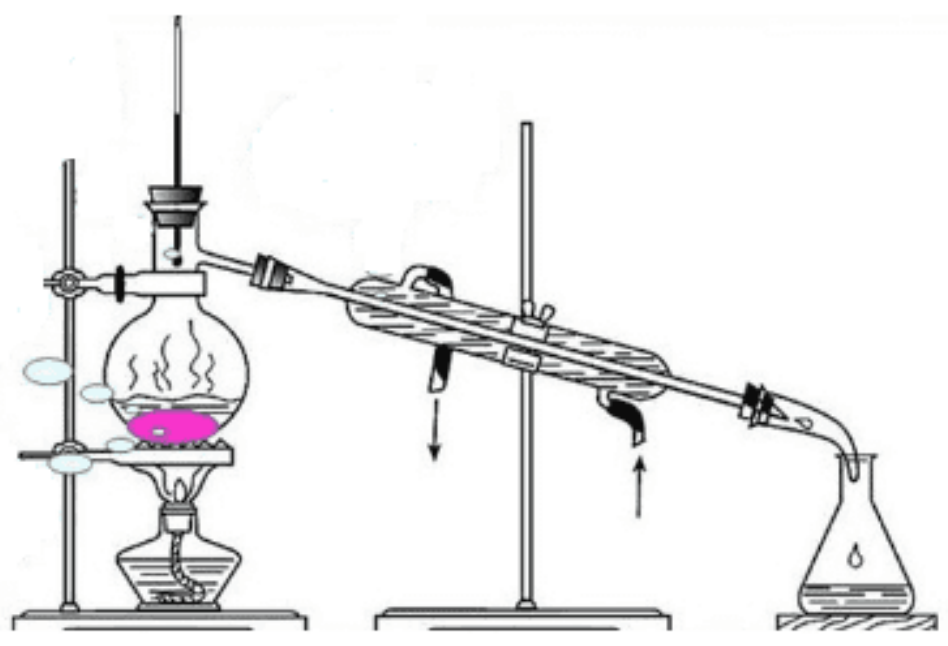

Fonte: Hexis Científica, 2018.

$\mathrm{Na}$ saída do condensador foi alocada uma proveta com um alcoômetro de Gay-Lussac, para medição do teor alcoólico do destilado. Conforme os gases foram evaporando, resfriando e saindo pelo condensador foi realizada a medição do teor alcoólico, onde apresentaram teor alcoólico de $65^{\circ}$ a $70^{\circ} \mathrm{GL}$ os primeiros $5 \%$ de destilado obtido, sendo separado e correspondente a fração da cabeça. O destilado que contém graduação alcoólica entre $50^{\circ} \mathrm{GL}$ até $65^{\circ} \mathrm{GL}$ correspondente a fração do coração conhecida como cachaça foi separada da primeira fração em outro recipiente. Já o destilado com graduação alcoólica inferior a 50ªL, correspondente a fração de 
cauda também foi separada em outro recipiente e corresponde a $5 \%$ do volume total de destilado.

\section{PREPARO DO ETANOL COMBUSTÍVEL}

Após a obtenção dos resíduos de interesse (cabeça e cauda), os mesmos foram homogeneizados e colocados em uma proveta e, com o auxílio de um alcoômetro realizou-se a medição do teor de álcool da amostra, que foi anotado para posterior discussão.

Após utilizando as mesmas vidrarias utilizadas para a preparação da cachaça, conforme (Figura 4), encheu-se o balão de fundo redondo com aproximadamente cerca de 350,0 ml de cabeça e cauda que haviam sido homogeneizadas e em seguida iniciou-se o aquecimento pelo bico de Bunsen, controlando a temperatura pelo termômetro que também estava acoplado ao balão. Após determinado tempo observou-se a formação dos primeiros vapores e em seguida começou a sair as primeiras gotas de destilado. A operação foi encerrada até que o teor alcoólico do destilado obtido começou a diminuir.

\section{RESULTADOS E DISCUSSÃO}

O presente trabalho reproduziu em escala laboratorial o processo de produção da cachaça artesanal, de modo que todos os equipamentos utilizados têm a mesma função dos equipamentos utilizados em um alambique convencional, a fim de obter um destilado que se divide em 3 partes, cabeça (resíduo), coração (cachaça) e cauda (resíduo), onde a fração dos resíduos cabeça e cauda representam respectivamente $5 \%$ e $10 \%$ cada uma, do volume final de destilado, seguindo a fundamentação teórica descrita por Daolio (2012). Após a produção da cachaça experimentalmente obtevese os dados descritos na Tabela 1.

Tabela 1. Relação: Quantidade, Temperatura, Tempo para produção dos rejeitos.

Resultados 


\begin{tabular}{|c|c|}
\hline Quantidade de mosto antes destilação (balão) & $52,5 \mathrm{~mL}$ \\
\hline Quantidade total de destilado obtido & $5,3 \mathrm{~mL}$ \\
\hline $\begin{array}{l}\text { Quantidade de fração do resíduo cabeça (obtido após } \\
\text { destilação) }\end{array}$ & $44,6 \mathrm{~mL}$ \\
\hline $\begin{array}{l}\text { Quantidade de fração do coração ou cachaça } \\
\text { (obtido após destilação) }\end{array}$ & $2,6 \mathrm{~mL}$ \\
\hline $\begin{array}{l}\text { Quantidade de fração do resíduo cauda (obtido após } \\
\text { destilação) }\end{array}$ & \\
\hline Temperatura antes da destilação & $29^{\circ} \mathrm{C}$ \\
\hline Temperatura (ebulição) & $96^{\circ} \mathrm{C}$ \\
\hline Tempo total destilação & $40 \mathrm{~min}$. \\
\hline
\end{tabular}

Fonte: Próprio autor.

A etapa de processamento da cana-de-açúcar para obtenção da cachaça e de seus rejeitos foram realizadas por 40 vezes, até obter aproximadamente $320 \mathrm{~mL}$ de rejeitos (cabeça e cauda juntas), com um teor alcoólico de aproximadamente 59 GL, obedecendo rigorosamente os valores descritos na tabela anterior, a fim de se obter 
uma quantidade suficiente de rejeitos devido ao processo de destilação, cabeça e cauda, com as mesmas características para a realização de um novo processamento.

Em seguida, os rejeitos foram utilizados em novo processo de destilação, a fim de aumentar a graduação alcoólica de ambos. Conforme descrito por MEIRELES et al. (2010), para a obtenção do etanol combustível, deve ser utilizada uma coluna de fracionamento, que em escala real pode ser ilustrada conforme a Figura 5(A) e em escala laboratorial Figura 5(B). Este equipamento é indicado para separação de misturas azeotrópicas, que são misturas que contém dois ou mais líquidos, cuja composição na fase líquida não se altera após a operação de destilação, mas que são difíceis de separar por meio da destilação, visto que o ponto de ebulição é idêntica à do vapor em equilíbrio, formando solução com ponto de ebulição constantes. No caso da mistura de água e etanol conforme citado no trabalho, verificamos que a cada nova destilação dos rejeitos, cabeça e cauda, têm-se uma quantidade menor de água e maior de álcool, e para se obter um etanol de no mínimo 94,5 $\mathrm{GL}$, para ser considerado etanol combustível, têm no caso a formação de um Azeotrópo de Ebulição Mínimo. Este azeotrópo consiste em uma solução formada por uma concentração elevada de uma substância cujo ponto de ebulição é menor do o da outra substância da composição, e que devida a esta diferença que quantidade e pontos de ebulição a solução formada possui um ponto de ebulição inferior aos dois pontos de ebulição das substâncias separadamente, como, por exemplo, verifica-se que o ponto de ebulição do etanol é de $78,3^{\circ} \mathrm{C}$, o da água de $100^{\circ} \mathrm{C}$, ao nível do mar, tendo deste modo uma mistura contendo aproximadamente $90 \%$ de etanol e $10 \%$ de água, o ponto de ebulição desta substância passa a ser de $78,2^{\circ} \mathrm{C}$, temperatura esta inferior aos pontos de ebulição de ambas as substâncias separadamente (PORTAL SÃO FRANCISCO, 2018). A substância a ser destilada no equipamento de coluna de fracionamento, deve ser colocada em um balão de fundo redondo aquecido por uma manta aquecedora, que deve ser acoplado a coluna de fracionamento, ligada a um dispositivo de vidro que possui duas saídas nas quais, em uma delas é colocado um termômetro e a outra é conectada a um condensador reto ( Liebig), ligado a um sistema de circulação de água que promove a condensação dos vapores, que após passarem 
pela mudança de estado, vapor-líquido, podem ser alocados em uma proveta para posterior medição do graduação alcoólica.

Figura 5. A) Representação coluna de fracionamento escala real. B) Representação coluna de fracionamento escala laboratorial.

A)

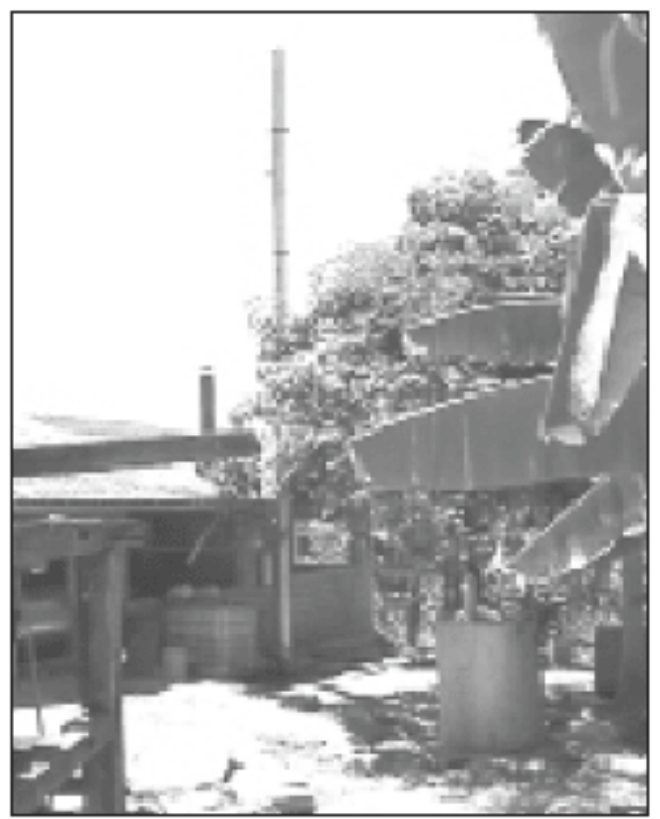

B)

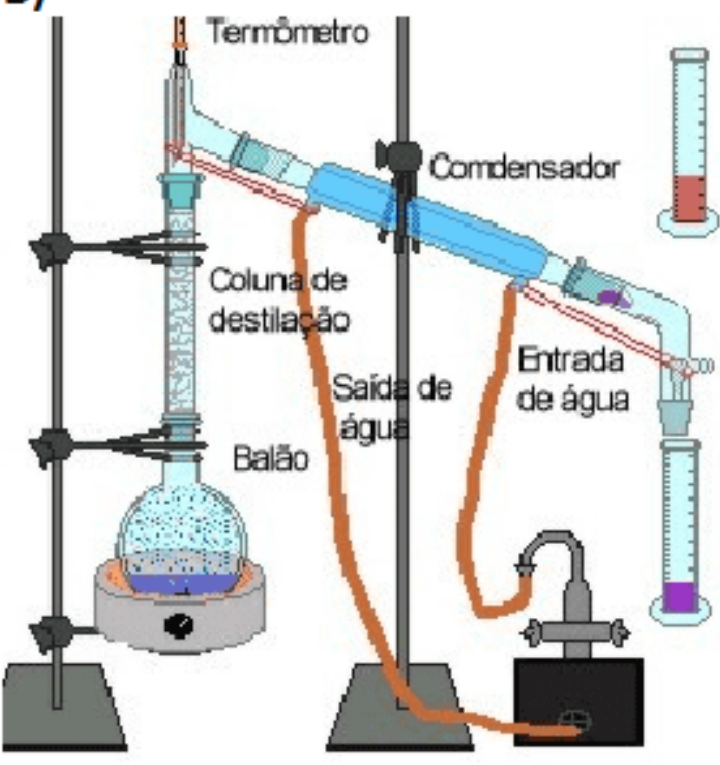

Fonte: MEIRELES et al., 2009 e BIOLOGIA, 2018.

Devido a falta de disponibilidade para a utilização da aparelhagem indicada por (MEIRELES et al.,2010) e também por tentar simular o equipamento que os pequenos produtores possuem em mãos, não foi utilizada a aparelhagem mencionada conforme modelo da Figura 5. Assim, foi necessária a realização da redestilação dos resíduos cabeça e cauda a fim de aumentar a graduação alcoólica de ambos, por meio do aparelho de destilação simples, também utilizado na produção da cachaça artesanal. Os dados são apresentados na Tabela 2.

Tabela 2. Relação: Quantidade, Temperatura, horário, pH e teor alcoólico.

\begin{tabular}{|l|l|l|}
\hline Grandeza & $\begin{array}{l}\text { Unidade de } \\
\text { medida }\end{array}$ & Resultados \\
\hline Redestilação
\end{tabular}

Disponível em: https://www.nucleodoconhecimento.com.br/engenharia-quimica/obtencao-doetanol 


\begin{tabular}{|c|c|c|c|c|}
\hline & & $1^{\mathrm{a}}$ & $\mathbf{2}^{\mathbf{a}}$ & $3^{a}$ \\
\hline $\begin{array}{l}\text { Quantidade de rejeitos } \\
\text { (cabeça e cauda) antes da } \\
\text { destilação (balão) }\end{array}$ & Mililitro - $\mathrm{mL}$ & 100 & 100 & 100 \\
\hline $\begin{array}{l}\text { Quantidade de destilado } \\
\text { obtido }\end{array}$ & Mililitro - mL & 50 & 49 & 49 \\
\hline $\begin{array}{l}\text { Temperatura antes da } \\
\text { destilação } \\
\text { Temperatura (ebulição) }\end{array}$ & $\begin{array}{l}\text { Grau Celsius - }{ }^{\circ} \mathrm{C} \\
\text { Grau Celsius - }{ }^{\circ} \mathrm{C}\end{array}$ & $\begin{array}{l}80 \\
19: 55\end{array}$ & $\begin{array}{l}79 \\
20: 10\end{array}$ & $\begin{array}{l}79 \\
20: 10\end{array}$ \\
\hline $\begin{array}{lll}\text { Horário antes } & \text { da } \\
\text { destilação } & & \end{array}$ & $\begin{array}{l}\text { Hora - } \mathrm{h} \\
\text { Hora - } \mathrm{h}\end{array}$ & $20: 40$ & $20: 50$ & $20: 40$ \\
\hline $\begin{array}{l}\text { Horário após da } \\
\text { destilação }\end{array}$ & Gay Lussac - ${ }^{\circ} \mathrm{GL}$ & $\begin{array}{l}59 \\
80\end{array}$ & $\begin{array}{l}59 \\
81\end{array}$ & $\begin{array}{l}59 \\
80\end{array}$ \\
\hline $\begin{array}{l}\text { Teor alcoólico (antes) } \\
\text { Teor alcoólico (depois) }\end{array}$ & Gay Lussac - ํL & 5,00 & 6,00 & 6,00 \\
\hline $\mathrm{pH} d \mathrm{c}$ & & & & \\
\hline
\end{tabular}

Fonte: Próprio autor.

Conforme pode-se verificar nos resultados apresentado nas Tabela 2, o teor alcoólico máximo obtido no experimento em questão foi de $80^{\circ} \mathrm{GL}$. Conforme legislação o teor alcoólico mínimo para o etanol combustível comercializado é 94,5 GL (MONTEIRO, 2010). Dessa forma, é possível identificar que o valor alcoólico obtido na amostra, após a redestilação, apesar de ter aumentado significativamente passando de $59^{\circ} \mathrm{GL}$ para $80^{\circ} \mathrm{GL}$, ficou distante do valor mínimo necessário para se obter o etanol combustível. A fim de tentar elevar ainda mais o teor alcoólico, foi realizado novamente

Disponível em: https://www.nucleodoconhecimento.com.br/engenharia-quimica/obtencao-doetanol 
o procedimento de redestilação, subdivididas em 3 bateladas, cuja amostra em questão, possui teor alcoólico $80^{\circ}$ GL. A Tabela 3 apresenta os resultados.

Tabela 3. Relação: Quantidade, Temperatura, horário, pH e teor alcoólico.

\begin{tabular}{|c|c|c|c|c|}
\hline \multirow[t]{2}{*}{ Grandeza } & \multirow{3}{*}{$\begin{array}{l}\text { Unidade de } \\
\text { medida }\end{array}$} & \multirow{2}{*}{\multicolumn{3}{|c|}{$\begin{array}{l}\text { Resultados } \\
\text { Redestilação }\end{array}$}} \\
\hline & & & & \\
\hline & & $1^{a}$ & $2^{a}$ & $3^{a}$ \\
\hline $\begin{array}{l}\text { Quantidade de rejeitos } \\
\text { (cabeça e cauda) antes da } \\
\text { destilação (balão) }\end{array}$ & Mililitro - $\mathrm{mL}$ & 50 & 50 & 50 \\
\hline $\begin{array}{l}\text { Quantidade de destilado } \\
\text { obtido }\end{array}$ & Mililitro - mL & 25 & 24 & 24 \\
\hline $\begin{array}{l}\text { Temperatura antes da } \\
\text { destilação }\end{array}$ & $\begin{array}{l}\text { Grau Celsius - }{ }^{\circ} \mathrm{C} \\
\text { Grau Celsius - }{ }^{\circ} \mathrm{C}\end{array}$ & 80 & 80 & 79 \\
\hline Temperatura (ebulição) & & $21: 30$ & $22: 00$ & $21: 20$ \\
\hline $\begin{array}{lll}\text { Horário antes } & \text { da } \\
\text { destilação } & & \end{array}$ & Hora - $\mathrm{h}$ & $21: 50$ & $22: 25$ & $21: 50$ \\
\hline $\begin{array}{lll}\text { Horário após } & \text { da } \\
\text { destilação } & & \end{array}$ & Gay Lussac - ${ }^{\circ} \mathrm{GL}$ & $\begin{array}{l}80 \\
87\end{array}$ & $\begin{array}{l}81 \\
87\end{array}$ & $\begin{array}{l}80 \\
86,5\end{array}$ \\
\hline Teor alcoólico (antes) & Gay Lussac - ํL & 6,00 & 6,00 & 6,00 \\
\hline Teor alcoólico (depois) & & & & \\
\hline pH do destilado & & & & \\
\hline
\end{tabular}

Fonte: Próprio autor. 
Foram realizadas algumas comparações em relação as características físico-químicas do produto obtidos em escala laboratorial com uma amostra de etanol combustível coletada em um posto de combustível. Os dados são mostrados na Tabela 4. Verificase que algumas características estão bem próximas como pH e condutividade.

Tabela 4. Relação: Condutividade, densidade, pH e teor alcoólico.

\begin{tabular}{|l|l|l|l|}
\hline Grandeza & $\begin{array}{l}\text { Unidade de } \\
\text { Medida }\end{array}$ & $\begin{array}{l}\text { Etanol } \\
\text { Combustível }\end{array}$ & Rejeito \\
após redestilação
\end{tabular}

Fonte: Próprio autor.

Mesmo após a realização de duas destilações consecutivas dos rejeitos do processo de destilação da cachaça, cabeça e cauda, não foi possível atingir o teor alcoólico necessário para o destilado final ser considerado etanol combustível, apesar do aumento significativo deste valor que era inicialmente $59^{\circ} \mathrm{GL}$ passando para $87^{\circ} \mathrm{GL}$. Isso se deve possivelmente ao equipamento utilizado nos procedimentos, que se trata de um sistema de destilação simples, diferente do equipamento de destilação fracionada que havia sido citado por (MEIRELES et al.,2010). O sistema de destilação fracionada diferencia-se do sistema simples, por conter a coluna de fracionamento, cuja principal função consiste na separação de misturas azeotrópicas, que tem como particularidade pontos de ebulição muito próximos, como no caso da água e do álcool presentes neste trabalho. $\mathrm{O}$ etanol possui ponto de ebulição em torno de $78,37^{\circ} \mathrm{C}$ e a água $100 \stackrel{\circ}{\circ}$, ambos em relação ao nível do mar. É importante ressaltar que para uma melhor adequação da coluna de fracionamento para um determinado processo deve-se calcular o número de pratos teóricos necessários para que a separação seja eficiente. O número de pratos teóricos refere-se ao número de estágios necessários

Disponível em: https://www.nucleodoconhecimento.com.br/engenharia-quimica/obtencao-doetanol 
para alcançar um certo grau de separação dos componentes de uma determinada solução original. A Figura 6 mostra uma ilustração de pratos teóricos sendo representados pelos números 1,2,3,4.

Figura 6. Representação do número de pratos teóricos em determinado processo.

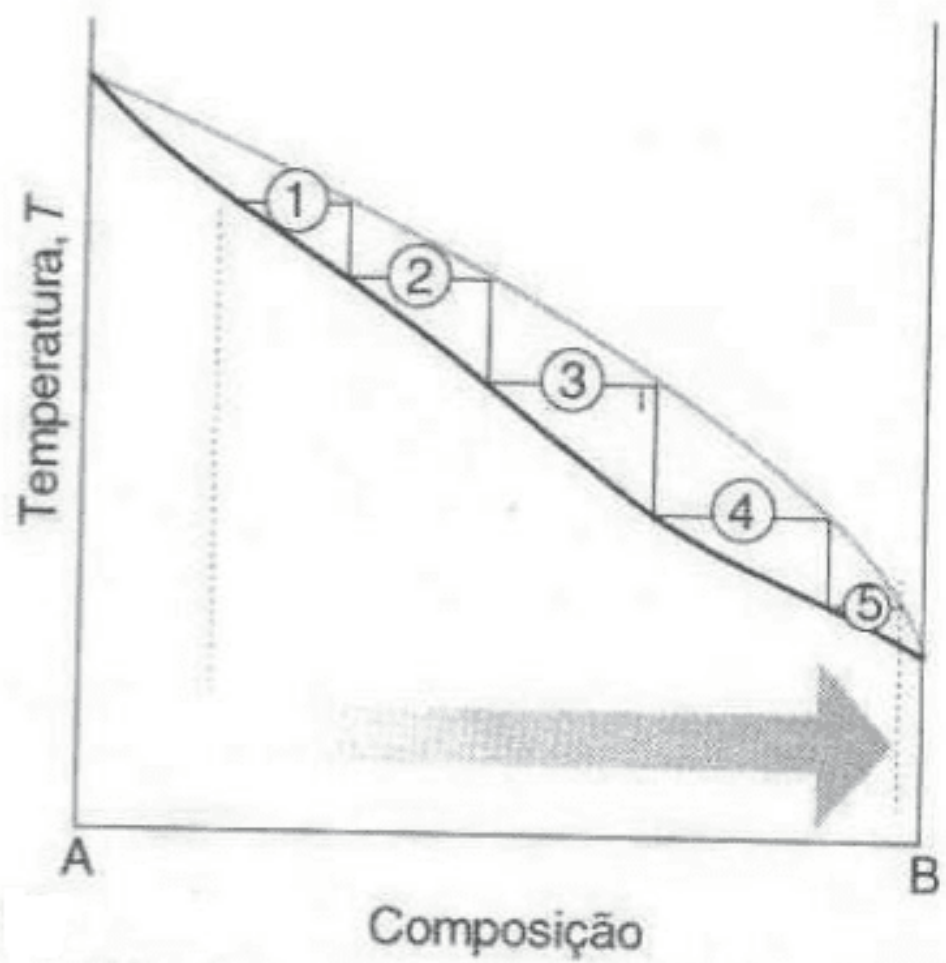

Fonte: OLIVEIRA et al, 2018

Dentro da coluna de fracionamento, existem bolinhas de porcelana ou mesmo em alguns casos, diversos dobramentos do vidro que são responsáveis por impedir a passagem dos vapores, onde o vapor menos volátil ao tocar as paredes frias do vidro ou tentar passar entre as bolinhas de porcelana, se condensam e voltam para o balão, deste modo retém estes vapores por mais tempo, promovendo diversas redestilações de uma só vez. Podemos identificar na Figura 7(A e B), a diferença entre um destilador simples e uma coluna de fracionamento. 
Figura 7. (A) Representação coluna fracionada e (B) Representação de um destilador simples.

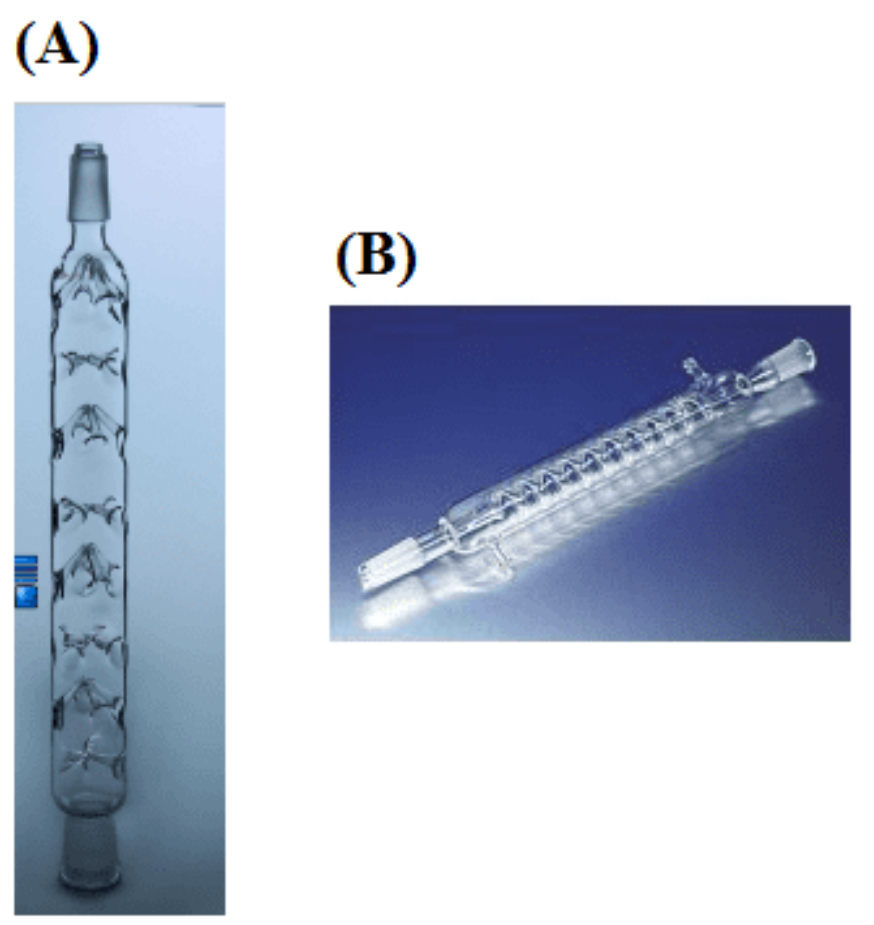

Fonte: Hermonlab, 2018 e Hexis Científica, 2018.

\section{CONCLUSÕES}

A partir do processo de destilação simples, denominado alambique foi possível produzir a cachaça artesanal, além das outras duas frações, chamadas de cabeça e cauda. Essas frações são consideradas resíduos e foram reutilizadas para obter o etanol combustível.

As frações cabeça e cauda com teor alcoólico de $59^{\circ} \mathrm{GL}$ passaram por um processo de resdestilação simples apresentando teor alcoólico entre $80^{\circ} \mathrm{GL}$ e $87^{\circ} \mathrm{GL}$. Houve um aumento no teor de álcool, porém, para ser considerado etanol combustível o grau alcoólico deve estar por volta de $94,5^{\circ} \mathrm{GL}$. Essa diferença se deve ao sistema de destilação utilizado, a destilação simples é indicada para separar substâncias com maiores diferenças no ponto de ebulição, o que não ocorre no experimento 
apresentado, já que é composto de duas substâncias com pontos de ebulição muito próximos, como o do etanol e água. O sistema adequado para obter a graduação alcoólica desejada para obter o etanol combustível é um destilador com coluna fracionada.

No entanto, utilizou-se o método de destilação simples, o mesmo usado pelos produtores de cachaça artesanal, assim, cada produtor pode reutilizar os rejeitos cabeça e cauda para obter etanol sem precisar alterar o sistema de produção. Embora o etanol não apresente o teor alcoólico desejado para ser considerado combustível, ele pode ser usado na limpeza dos equipamentos.

\section{REFERÊNCIAS}

ALAMBIQUE DA CACHAÇA. História da Cachaça. Disponível em: < http://www.alambiquedacachaca.com.br/artigo.php?recordID=2\&artigo=A\%20Hist\%F 3ria\%20da\%20Cacha\%E7a>. Acesso em: 09 abril 2018.

BIOLOGIA. Destilação Fracionada. Disponível em: < https://www.sobiologia.com.br/conteudos/Oitava_quimica/materia17.php >. Acesso em: 25 de outubro 2018.

DAOLIO, Edson. Processo de Fabricação: Cachaça. Notas de Aula. 5 p, 25 maio 2012.

FONTANETTI, Carmen. Silvia; BUENO, Odair. Correa. Cana-de-Açúcar e seus impactos: uma visão acadêmica.; Instituto de Biociências, campus Rio Claro; editora canal 6; $1^{\circ}$ edição, UNESP, Bauru-SP; 2017.

HEXIS CIENTÍFICA. Equipamentos Laboratório. Disponível em: $<$ http://www.hexis.com.br/produtos?search=sacarimetro+brix>. Acesso em: 25 maio de 2018. 
HERMONLAB. Equipamentos Laboratório. Disponível em: < https://hermonlab.com.br/4429344-Coluna-Vigreux-25-x-300-MM>. Acesso em: 31 de outubro 2018.

LEITE, Rogério Cerqueira; CORTEZ, Luís Augusto Barbosa. O etanol combustível no Brasil. Embrapa, 2008. Disponível em: <https://www.agencia.cnptia.embrapa.br/Repositorio/etanol3_000g7gq2cz702wx5ok Owtedt3xdrmftk.pdf> . Acesso em: 16 de maio 2018.

MEIRELES, Wesley Antunes; OLIVEIRA, Valdenir Pereira; FERREIRA, Lília Cristina; SOARES, Klícia M. Marinho; ABREU, Lenir. Aproveitamento de resíduos da fabricação de cachaça para produção de etanol. Revista Agrogeoambiental p.28 a 35- Abril 2010.

MONTEIRO, Cristiane. Nova Regulamentação ANP que Especifica Qualidade do Etanol Combustível. ANP, 2010. Disponível em: http://www.udop.com.br/download/legislacao/comercializacao/institucional_site_juridi co/revisao_resolucao_36_2005.pdf>. Acesso em: 30 de outubro 2018.

NOVA CANA. A produção de cana-de-açúcar no Brasil e no mundo. Disponível em: < https://www.novacana.com/cana/producao-cana-de-acucar-brasil-e-mundo/ >. Acesso em: 25 maio 2018.

OLIVEIRA, Consuelo Ribeiro; GARÍGLIO, Helder A. Aquino; RIBEIRO, Morgana Menezes; ALVARENGA, Miriam Souza Pinto; MAIA, Francisco Xavier. Cachaça de alambique: Manual de boas práticas ambientais e de produção. Convênio de cooperação técnica seapa/semad/ampaq/feam/ima; junho, 2005. Disponível em:< http://www.feam.br/images/stories/arquivos/Manual_de_Cachaca_040805.pdf >. Acesso em: 10 maio 2018. 


\section{ANEXO}

Figura Em Inglês

Figura 5

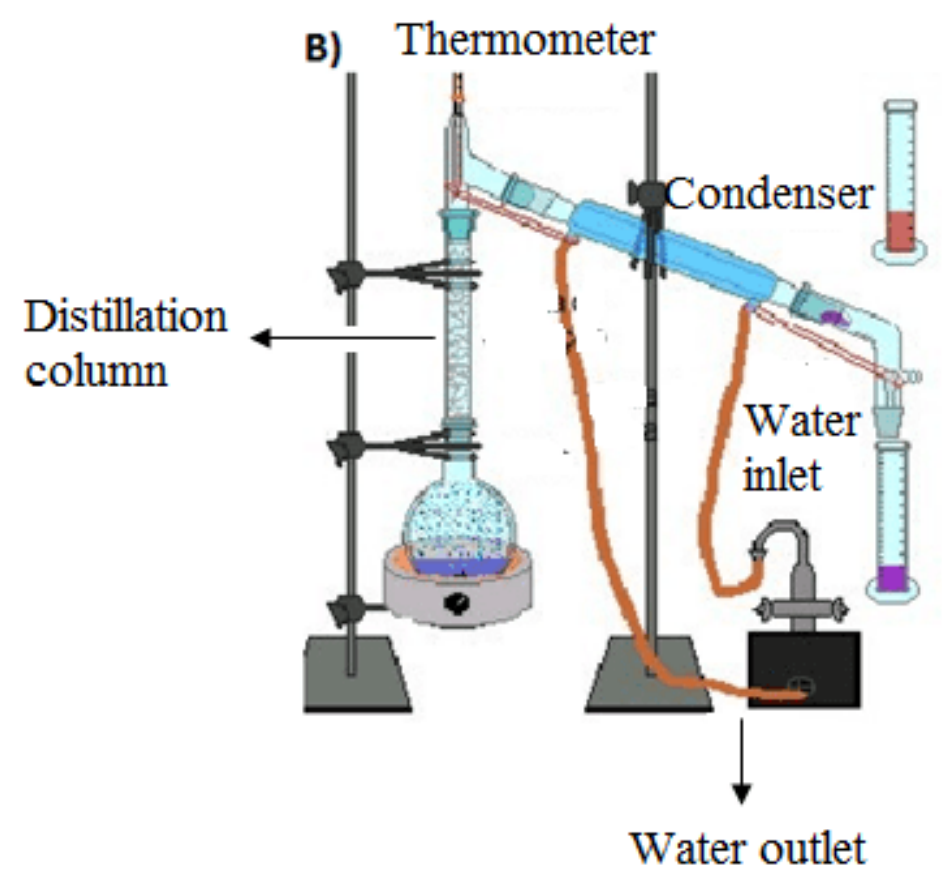

Enviado: Setembro, 2019.

Aprovado: Abril, 2020. 